\title{
En los márgenes de la periferia. Mundo popular urbano y condiciones de vida en la ciudad de Jujuy (Argentina) en la década de 1930
}

\author{
In the margins of the periphery. Popular urban world and living \\ conditions in the city of Jujuy (Argentina) in the 1930s
}

\author{
ADRIANA KINDGARD \\ Universidad Nacional de Jujuy, CONICET \\ a.kin@imagine.com.ar
}

Resumen: Las repercusiones en la sociedad de la crisis mundial de 1929 colocaron en un lugar privilegiado de la agenda oficial del Gobierno argentino a la llamada "cuestión social". Desde el Estado se pusieron en funcionamiento, a lo largo del país, estructuras administrativas destinadas a intervenir en áreas como la educación, la salud y la vivienda. La tendencia a encarar los estudios de las políticas sociales desde perspectivas de macronivel o, en el caso de Argentina, de circunscribir el análisis al ámbito metropolitano de Buenos Aires, encuentra un contrapunto en trabajos que focalizan la atención en espacios locales, mostrando la diversidad de escenarios y realidades a tomar en cuenta. Con la expectativa de contribuir a dilucidar la trama de factores que median entre la disposición de los actores estatales para desplegar políticas de intervención en la esfera social y la capacidad de las mismas de impactar en las capas de la población a las que van dirigidas, proponemos una aproximación a las condiciones de vida de aquellos sectores populares que habitaron la ciudad de Jujuy en esos años críticos y que, por diversos motivos, permanecieron fuera de los mecanismos de integración social implementados.

Palabras clave: Años treinta, ciudad de Jujuy (Argentina), marginalidad, condiciones de vida, políticas sociales.

Abstract: The impact on the society of the 1929 global crisis put the "social question"
in a privileged place within the official government agenda in Argentina. The State put
into operation, throughout the national territory, administrative structures to intervene in
areas such as education, health and housing. The tendency to approach the social policy
studies from perspectives of macro level or dealing exclusively with the metropolitan
area of Buenos Aires, as the case of Argentina, finds a counterpoint in works, which focus
attention on local areas, showing the diversity of scenarios and realities to consider. It
should be noted the weaving of factors that affect the state actors' willingness to socially
deploy intervention policies and their ability to impact the layers of population to which
they are addressed. For all this, we propose an approach to the living conditions of those

Recibido: 4 de noviembre de 2016; aceptado: 16 de enero de 2017; publicado: 21 de septiembre de 2017. Revista Historia Autónoma, 11 (2017), pp. 161-178.

e-ISSN: 2254-8726; DOI: https://doi.org/10.15366/rha2017.11.008 
popular sectors that inhabited the city of Jujuy in those critical years and that, for various reasons, remained outside the social integration mechanisms implemented.

Keywords: The 30s, city of Jujuy (Argentina), marginality, living conditions, social policies.

\section{Introducción}

En 1932 el entonces gobernador de Jujuy, Fenelón Quintana, aludía en su discurso anual ante la Cámara de Diputados a la grave situación económica que la provincia atravesaba como consecuencia "de la crisis que invade al país" y llamaba la atención sobre la magnitud del problema social que la misma entrañaba, expresada de modo elocuente en los

\footnotetext{
“[...] centenares de personas apostadas en las Galerías de la Casa de Gobierno pidiendo un empleo o simplemente trabajo [...]. No sabía en determinado momento si proveer la olla popular o francamente embarcarme en la inversión de fondos no previstos en la medida necesaria en nuestro presupuesto, fondos tampoco disponibles en nuestras arcas"1.
}

En el extremo norte de Argentina, y a casi dos mil kilómetros de distancia de las principales áreas económicas y los centros de decisión política, Jujuy era hacia la década de 1930 un espacio periférico $^{2}$. En su territorio se distinguen cuatro grandes regiones internas: la de los Valles Centrales al sur, donde se encuentra la ciudad capital; la de los Valles Subtropicales hacia el este; la Quebrada de Humahuaca, en la zona central, que se extiende hacia el norte, y la

\footnotetext{
${ }^{1}$ Mensaje del Gobernador Fenelón Quintana, 1 de mayo de 1932, p. 16. Archivo Histórico de la Legislatura de la Provincia de Jujuy [en adelante, AHLJ], Caja 1932.

${ }^{2}$ Existe gran asimetría entre las regiones que conforman el territorio argentino, configurándose una estructura centro-periferia donde esta última coadyuva a los procesos que se desenvuelven en el centro, garantizando por su parte la articulación con el mercado mundial. Hacia finales del siglo XIX el país se insertó en el mundo como proveedor de materias primas agropecuarias, conformando su mercado nacional a partir de una alianza entre los intereses agroexportadores y las oligarquías del interior. Girbal-Blacha, Noemí, "La Argentina fracturada. Una interpretación histórica del desarrollo agrario argentino en la primera mitad del siglo xx", en Revista de Historia Americana y Argentina, 40 (2003), pp. 5-44. Un análisis de las causas estructurales que subyacen a la conformación desigual del país puede hallarse en Manzanal, Mabel, "Descentralización, recursos y poder político de los gobiernos provinciales en Argentina”, en Restrepo, Darío (ed.), Historias de descentralización: transformación del régimen político y cambio en el modelo de desarrollo. América Latina, Europa y Estados Unidos, Bogotá, Universidad Nacional de Colombia, 2007, pp. 239-317. También Rofman analiza el problema de la desigualdad agravada y sostenida por el desequilibrio interregional. Rofman, Alejandro. "Las economías regionales. Un proceso de decadencia estructural", en Bustos, Pablo (comp.), Más allá de la estabilidad, Buenos Aires, Fundación Friedrich Ebert, 1993, pp. 161-189.
} 
Puna - parte del Altiplano andino- que abarca los departamentos del oeste y del norte. La producción azucarera proporcionó la base de la integración de la provincia al mercado nacional capitalista, proceso que ocasionó la decadencia de la tradicional red comercial orientada hacia Bolivia y el Pacífico que desde la Colonia había sido el eje dinamizador de la economía. Alrededor de los años treinta el sector azucarero tenía gravitación clave en la formación del producto bruto interno jujeño pero su incidencia en el desarrollo de la región era relativa ya que el grueso de las ganancias se derivaba hacia Buenos Aires, donde residían los principales accionistas de las compañías.

Las repercusiones de la crisis en la esfera de lo social habían provocado en la mayor parte del mundo occidental un cambio de rumbo en las políticas públicas, en el sentido de derivar mayores recursos hacia programas de asistencia y de mejora de las condiciones de vida de la población. En Argentina este proceso fue conducido por los gobiernos de signo conservador que accedieron al poder en 1930, tras el alzamiento militar que derrocó al presidente del Partido Radical, Hipólito Yrigoyen. El Estado nacional se dispuso a intervenir ampliamente en el terreno social, lo que incluyó también la injerencia en los conflictos laborales.

La tendencia a encarar los estudios de las políticas sociales desde perspectivas de macronivel o, en el caso de Argentina, de circunscribir el análisis al ámbito metropolitano de Buenos Aires, ha encontrado un interesante contrapunto en la serie de trabajos que focalizan la atención en espacios provinciales o locales, mostrando la diversidad de escenarios y realidades a tomar en cuenta y poniendo en agenda la necesidad de complejizar muchas de las presunciones de una historia nacional con vocación generalizadora ${ }^{3}$.

Acudiendo a fuentes poco recorridas hemos procurado arrojar luz sobre los alcances concretos del intervencionismo social de la época, inquiriendo en torno a la capacidad del Estado nacional para llegar con sus políticas a las áreas periféricas del país -en este caso a la ciudad de Jujuy - y hasta las capas más vulnerables de la población. Así, el cruce de información estadística con datos dispersos en la prensa y en expedientes de algunas instituciones públicas y, particularmente, la apelación a una fuente peculiar — las "cartas de pobreza"- nos han permitido acceder a ciertas facetas de la experiencia social de aquellas y delinear mejor sus perfiles. Estos no eran del todo asequibles a partir de los resultados de los relevamientos censales focalizados en registrar el trabajo formal que, por lo demás, quedaban desdibujados al homogeneizarse bajo las cifras de hacinamiento, analfabetismo y mortalidad infantil que revelaban la magnitud de su presencia en el espacio urbano ${ }^{4}$.

\footnotetext{
${ }^{3}$ Un balance de los abordajes de la historia de las políticas sociales en el país puede hallarse en Bohoslavsky, Ernesto, "El Estado argentino y sus políticas públicas (1880-1943): algunas discusiones historiográficas", en Sociedad y Economía, 26 (2014), pp. 17-40. «http://www.scielo.org.co/pdf/soec/n26/n26a02.pdf» [consultado el 9 de octubre de 2016]. Un interesante estudio de un caso provincial en el período que nos ocupa puede hallarse en Ortiz Bergia, María José, De caridades y derechos. La construcción de políticas sociales en el interior argentino. Córdoba (1930-1943), Córdoba, Centro de Estudios Históricos Profesor Carlos S. A. Segreti, 2009.

${ }^{4}$ Sobre las omisiones de la estadística sociolaboral véase González Bollo, Hernán, "La cuestión obrera en números: la estadística socio-laboral argentina y su impacto en la política y la sociedad, 1895-1943”, en Otero, Hernán (ed.),
} 


\section{Clivajes sociales en la ciudad}

Como otras ciudades nacidas en la Colonia, la de Jujuy se había fundado en un valle fácil de defender de ataques indígenas, en la confluencia de los ríos Grande y Xibi-Xibi (o río Chico). Llamada durante la época que analizamos simplemente Jujuy, la ciudad seguía la disposición de una cuadrícula, entre las márgenes de ambos ríos. ${ }^{5}$ La parte antigua, emplazada en un sitio alto enmarcado por estos dos brazos de agua, seguía aún entonces representando para la mayoría de sus habitantes la ciudad "propiamente dicha". Allí, las residencias de edificación moderna y las obras de urbanización estaban ya destruyendo las paredes de adobe de las casas coloniales: "La ciudad ha empezado a quebrar su ritmo visual. Ha de adquirir pronto el ritmo nuevo que busca, y será otra Jujuy en el mismo sitio, con el mismo cuadro incambiable de sus montañas y sus ríos".

La ciudad de Jujuy era en la época la única "urbe" en todo el territorio provincial. Sus alrededores, a escasos kilómetros del casco céntrico, ofrecían un panorama variado. Cruzando el río Grande se extendía hacia el norte la "banda de Los Perales". Hacia el sur "Villa Elisa", con sus quebradas interiores y, más allá, la zona de monte lindante con la margen derecha del río Chijra; a partir de su margen izquierda comenzaba el paraje denominado "Bajo de Alviña". Todos estos lugares, en donde se intercalaban bosques, sembradíos y áreas de pastura, estaban salpicados de humildes viviendas que se levantaban lo mismo en terrenos fiscales que en las vastas tierras que se extendían más allá del radio inmediato de las casonas solariegas, y cuyos dueños pocas veces delimitaban con alambrados y tranqueras? ${ }^{7}$ Sobre la margen derecha del río Grande - esto es, en los terrenos bajos entre el lecho del mismo y las vías del ferrocarril Central Norte- se habían formado sendos villorrios: "Villa Tramontini", al norte, y "Villa Belgrano", al sur. Un testigo ocasional de mediados de la década, que visitó la ciudad durante tres días, la describió entonces así: "mucho menos basta para verla [...]. Yo conocí a Jujuy de noche. De día la impresión es menos rica. El paseo sin concluir, las feas casuchas del bajo, estorban el placer de mirar" ". De la situación de aislamiento en la que se hallaron a lo largo del período aquí analizado las poblaciones que habitaban estas villas de los bajos, daban prueba en 1940 las palabras de un diputado del Partido Radical:

"La falta de agua corriente y el mal estado de las calles son notas características de los barrios obreros que rodean la ciudad. En Villa Belgrano donde se aloja

El mosaico argentino. Modelos y representaciones del espacio y de la población, siglos XIX-XX, Buenos Aires, Siglo XXI, 2004, pp. 331-381.

${ }^{5}$ A partir del 19 de abril de 1950 (fecha del $357^{\circ}$ aniversario de su fundación) la ciudad recuperaría en parte su nombre primigenio, pasando a denominarse San Salvador de Jujuy. El nombre original impuesto por su fundador, Juan Ramírez de Velazco, era "San Salvador de Velazco en el Valle de Jujuy".

${ }^{6}$ Bouilly, Víctor, "Film jujeño", en Jujuy, 5 (1937), p. 19.

${ }^{7}$ Puede verse Romano, Carolina, Jujuy de antaño, Jujuy, edición de la autora, 2000.

${ }^{8}$ Bouilly, Víctor, "Film jujeño..." op. cit., p. 19. 
una cantidad numerosa de familias, las incomodidades son mayores. Carece de una bajada para el tráfico automotriz o de cualquier otra índole. Las jardineras que hacen el reparto del pan o de la leche no pueden llegar hasta allí. Existe un aislamiento inadmisible",

En el extremo opuesto de la ciudad, atravesando el río Xibi-Xibi, el entorno natural era bastante similar: manchones de bosques; en las planicies, los cultivos y el ganado y los ranchos de las gentes que habitaban el lugar. Villa "Las Rosas" se levantaba sobre la margen derecha del río, entre las vías del ferrocarril y el camino nacional. A juzgar por las referencias halladas, era este un núcleo particularmente marginal, donde "no llega el agua y ni un foco alumbra las callejas enlodadas. Como si no tuvieran bastante con esto las humildes familias que tienen la desgracia de habitar por esos lares, ahora la municipalidad les instala un basural"10.

La franja de terreno más cercana al río presentaba ya a inicios de los años treinta rasgos suburbanos definidos. En efecto, la llamada "banda del río Chico" había empezado a poblarse hacia mediados de la década anterior, en un proceso de ritmo veloz impulsado por la incorporación al mercado inmobiliario de parte de las tierras de las familias Claros y Castañeda ${ }^{11}$, subdivididas en pequeños lotes. En el período que nos ocupa, en esta zona "bandeña" podían diferenciarse, de norte a sur, las barriadas populares de Cuyaya, Castañeda, Gorriti y San Pedrito, que crecían más allá de toda previsión, siendo el fenómeno objeto de recurrentes comentarios en la prensa local:
“[...] hay un serio inconveniente en las construcciones de las viviendas que ya forman cadena en las distintas villas denominadas Villa Gorriti, San Pedrito, Castañeda y Cuyaya, puesto que ellas son construidas sin tener ninguna línea ni nivel adecuado, que da aspecto de pueblos modernos y bien organizados [...] la mayoría son casas de obreros que han costado "un ojo de la cara" para comprar un pequeño lote y levantar su hogar [...]"12.

Los dos ríos que abrazaban la ciudad para ir a unirse, a pocas cuadras de la plaza principal, en la llamada "Punta de Diamante", materializaban en el espacio una diferenciación social, al separar - y distinguir jerárquicamente - a las familias que residían en el centro de aquellas que poblaban los suburbios ${ }^{13}$. En 1932, un periódico local tomaba por blanco a las casas de inquilinato

\footnotetext{
${ }^{9}$ AHLJ, Diario de Sesiones de la Honorable Legislatura de la Provincia, Sesión del 20 de agosto de 1940 (diputado Horacio Guzmán), p. 122.

${ }^{10}$ Crónica, 3 de febrero de 1933, p. 4.

${ }^{11}$ Se trataba de dos familias pertenecientes a la élite tradicional de Jujuy, vinculadas al ambiente político local.

${ }^{12}$ Crónica, 11 de enero de 1936, p. 1. San Pedrito era la menos densamente poblada. Nicolini, Alberto y Marta Silva, San Salvador de Jujuy, 1561-1961. Desarrollo urbano y arquitectónico, Tucumán, Universidad Nacional de Tucumán, 1973.

${ }^{13}$ En su conocida obra, Manuel Castells habla de "segregación urbana" para hacer referencia a aquellos casos en que la distancia social tiene una fuerte expresión espacial, tendiéndose a "la organización del espacio en zonas de fuerte homogeneidad social interna y de fuerte disparidad social entre ellas, entendiéndose esta disparidad no sólo en términos de diferencia, sino de jerarquía". Castells, Manuel, La sociedad red, Madrid, Alianza Editorial, 2000, p. 204.
} 
del centro de la ciudad, reclamando a los poderes públicos por su presencia y haciéndose eco de las miradas prejuiciosas de los vecinos:

“[...] esas viviendas obreras siguen siendo, como hace 10 años atrás, los mismos sitios inmundos en donde las personas que los habitan están siempre expuestas a ser atacadas por cualquier enfermedad, víctimas del contagio o de la propia falta de limpieza que convierte a esos llamados conventillos en permanentes y peligrosos focos de infección"14.

A lo largo de la década la prensa fue canal de expresión de quienes se arrogaban el derecho de exclusividad sobre el espacio urbano entre los ríos, haciéndolo extensivo al de gozar, sin interferencias, de una estética que percibían amenazada. “QQuiénes son los nuevos habitantes que transforman tan profundamente la ciudad?", se preguntaba García Vargas buscando en los editoriales de los diarios las claves de acceso a los imaginarios urbanos: "Los cambios se relacionan con un aumento desusado de la población, pero notablemente no se menciona a inmigrantes ni a extranjeros, en un silencio muy sugestivo"15.

En 1939 una ley provincial disponía la expropiación de los terrenos y las casas construidas en las Villas Belgrano y Tramontini, esgrimiendo razones de salubridad pública y de estética urbana. Aunque la medida no se concretaría, la ley dio cauce a propuestas de reubicación de los eventuales expropiados. Un empleado público, el ingeniero Ramón Alurralde, imaginaba construir "centenares de casas a lo largo de la Avenida 19 de Abril [a la vera del río Xibi-Xibi] donde hasta hoy es la vergüenza de la ciudad puesto que su aspecto actual es de sepulturas abandonadas" ${ }^{16}$. A estas proyecciones de corte modernista se oponían quienes buscaban restituir el orden y la armonía de la ciudad apelando a la tradición hispanista: "Por los paisajes que rodean a esta ciudad, debe darse a ella el conjunto armonioso y severo de la arquitectura sevillana, que puede realizarse para mayor hermosura con las combinaciones del morisco y el castellano" ${ }^{17}$.

En fin, en los suburbios de la ciudad, pero también desperdigados en las áreas de los márgenes del ejido urbano propiamente dicho - hacia los cuatro rumbos $-{ }^{18} \mathrm{y}$ seguramente en la miríada de conventillos del casco céntrico cuya propagación despertaba la encendida reacción de las élites, habitaban los sujetos que hemos constituido aquí en núcleo de nuestro análisis.

\footnotetext{
${ }^{14}$ La Opinión, 8 de abril de 1932, p. 4. Dos años después, decía el mismo diario: "Los conventillos tienen que ser, por su mal estado y por su increíble hacinamiento de personas, algo así como la entraña misma de la cual nacen y se propagan la mayor parte de las enfermedades que agotan a la gente del pueblo anónima”. La Opinión, 16 de agosto 1934 , p. 3.

${ }^{15}$ García Vargas, Alejandra, "Crónicas de fantasmas. Periódicos locales e imaginarios urbanos de San Salvador de Jujuy (1943-1945)", en Cuadernos, 24 (2004), p. 126. Dice García Vargas: "La «gente astrosa» [calificativo usado en una nota periodística de 1945] ha de ser radiada de la ciudad, al menos de la zona céntrica, ya que al quedar fuera de la mirada la sensación de orden puede ser restituida". García Vargas, Alejandra, "Crónicas de fantasmas..." op. cit., p. 139.

${ }^{16}$ La Voz del Norte, 19 de enero de 1940, p. 2.

${ }^{17}$ Citado en García Vargas, Alejandra, "Crónicas de fantasmas...” op. cit., p. 128.

${ }^{18}$ Nos referimos a las zonas de los "Altos de Quintana" o "Ciudad de Nieva", y de "La Tablada", hacia el norte; las ya mencionadas villas Tramontini y Belgrano, hacia el este; el área circundante a la "Punta de Diamante", en el sur, y las barrancas de la margen izquierda del Xibi-Xibi, hacia el oeste.
} 
2. Develaciones de la marginalidad

Al hablar de marginalidad imprimimos al concepto el sentido que, desde la llamada ecología urbana, le confiere el sociólogo argentino José Nun, y que hace referencia a la situación de aislamiento en que se encuentran aquellos habitantes de las ciudades que levantan viviendas precarias, generalmente sobre terrenos ilegalmente ocupados, y que carecen de servicios básicos ${ }^{19}$. Se configuran así áreas marginales (márgenes) dentro de una ciudad que —en el caso que nos ocupa y como lo insinúa el título del trabajo- es, al igual que el resto de la provincia, un espacio periférico con respecto a las regiones centrales del país ${ }^{20}$. Desde esta perspectiva, la marginalidad está estrechamente vinculada con la exclusión social, la vulnerabilidad y la pobreza.

La situación de crisis reinante en el país en los años treinta pondría en lugar privilegiado de la agenda oficial a la llamada "cuestión social". Como ha señalado Juan Suriano, los alcances del concepto se vinculan con las consecuencias sociales, laborales e ideológicas de la industrialización y problemáticas tales como las condiciones de la vivienda obrera, la salubridad, la atención médica, teniendo que ver también con la conformación de organizaciones destinadas a defender los intereses de la clase trabajadora ${ }^{21}$. En Argentina, los primeros debates sobre la cuestión social irrumpieron durante la crisis de 1890, que tuvo impacto profundo en el mundo del trabajo y exacerbó la conflictividad laboral. En ese contexto se configuró una corriente liberal reformista que promovió el intervencionismo estatal en torno al trabajo, la educación y la seguridad social22. Para Zimmermann, las raíces del intervencionismo social practicado décadas más tarde en el país deben rastrearse en esos años ${ }^{23}$. Una de las dimensiones de este temprano intervencionismo se vinculaba a las exigencias de los distintos factores de poder económico y tuvo como contracara el disciplinamiento laboral y la represión de la protesta obrera.

La "cuestión social" es ciertamente una categoría histórica; también lo es el concepto de intervencionismo social, estrechamente vinculado a aquella. En la década de 1930 la desocupación ocasionada por la gran crisis estuvo en el centro de las preocupaciones de políticos e intelectuales. También la salud pública irrumpía como prioridad en un contexto de propagación de enfermedades

\footnotetext{
${ }^{19}$ Nun, José, Marginalidad y exclusión social, México, Fondo de Cultura Económica, 2001.

${ }^{20}$ Un sentido similar de margen como espacialidad puede hallarse en Girbal-Blacha, Noemí, Vivir en los márgenes. Estado, políticas públicas y conflictos sociales. El Gran Chaco Argentino en la primera mitad del siglo XX, Rosario, Prohistoria, 2011.

${ }^{21}$ Véase Suriano, Juan, "Introducción: una aproximación a la definición de la cuestión social en Argentina”, en Suriano, Juan (comp.), La cuestión social en Argentina, 1870-1943, Buenos Aires, La Colmena, 2000.

${ }^{22}$ Véase Zimmermann, Eduardo, Los liberales reformistas. La cuestión social en la Argentina, 1890-1916, Buenos Aires, Sudamericana-Universidad de San Andrés, 1995. Este reformismo tuvo una de sus plasmaciones más importantes en el "Informe sobre el estado de las clases obreras en el interior de la República", elaborado en 1904 por Juan Bialet Massé.

${ }^{23}$ Zimmermann, Eduardo, "Un espíritu nuevo: la cuestión social y el derecho en Argentina (1890-1930)", en Revista de Indias, 257 (2013), pp. 81-106, DOI: 10.3989/revindias.2013.004. Para sostener este argumento el autor analiza los cambios en las concepciones, traducidos en el novedoso vocabulario conceptual del mundo jurídico argentino, ocurridos a principios del siglo xx frente a la irrupción de la nueva "cuestión social".
} 
endémicas, hacinamiento y malas condiciones de vida en las periferias urbanas. Las experiencias de intervencionismo que se desplegaron a nivel mundial generaron un fuerte consenso entre los contemporáneos sobre la necesaria participación estatal en la regulación económica y social ${ }^{24}$.

Las memorias del Poder Ejecutivo Nacional bajo la presidencia de Agustín P. Justo, inaugurada en 1932, dan cuenta de la importante actividad de la División de Estadísticas del Departamento Nacional del Trabajo en orden a realizar un estudio cuantitativo sobre las condiciones laborales y de vida de los trabajadores ${ }^{25}$. En cuanto a legislación laboral en la década, además de la temprana sanción de leyes destinadas a combatir la desocupación, el Congreso Nacional aprobó leyes tendientes a mejorar la situación del empleado de comercio, de las madres antes y después del parto, además de la legislación sobre jubilaciones y pensiones.

Si bien se desarrollaron a nivel nacional bases institucionales para la acción social oficial, los programas asistenciales se llevaron adelante en un sistema político que excluía la expresión de las aspiraciones populares de sus mecanismos decisorios. La actividad de asistencia de los gobiernos del treinta se enmarcó en un sistema de relaciones entre el Estado y la sociedad que tenía mucho de paternalista. El Estado nacional no fue reticente a las campañas específicamente benéficas. Tomando un ejemplo del ámbito provincial, todavía en 1942 el gobierno conservador de Jujuy destinaba la suma de $\$ 10000 \mathrm{~m} / \mathrm{n}$ para la distribución de ropa de abrigo a la "gente pobre" de Jujuy a fin de paliar el frío de la temporada invernal ${ }^{26}$.

Sobre todo en las áreas de salud y educación, las estructuras administrativas del Estado nacional canalizadas a los servicios sociales se ampliaron o hicieron más complejas, refinando las técnicas para la detección y medida de las carencias de la población. Durante la presidencia del general Justo se llevó adelante una reorganización integral de casi todas las oficinas del Departamento Nacional de Higiene. Acorde con el objetivo de combatir las endemias que afligían a algunas regiones del país, el Gobierno subvencionó las investigaciones sobre el paludismo, que realizaba el Dr. Carlos Alvarado, al frente de la Defensa Antipalúdica de Jujuy.

En 1934, "el paludismo se ha vuelto a convertir en una epidemia" decía una editorial del diario La Opinión:

\footnotetext{
"En esta ciudad y en todos los distritos del departamento Capital, los atacados por el flagelo suman centenares. No existe hogar donde no se encuentre más de un enfermo. En nuestro mundo infantil, sobre todo, el paludismo sigue haciendo innumerables víctimas. En presencia de tal estado de cosas, bien podría decirse que la campaña antipalúdica es un fracaso evidente"27.
}

\footnotetext{
${ }^{24}$ Distintos aspectos del intervencionismo social desplegado desde el Estado nacional en los años treinta han sido abordados en obras ya clásicas: Suriano, Juan (comp.), La cuestión social... op. cit.; Bertranou, Julián et al. (eds.), En el país de no me acuerdo. (Des)memoria institucional e historia de la politica social en la Argentina, Buenos Aires, Prometeo, 2004; Lvovich, Daniel y Juan Suriano (eds.), Las políticas sociales en perspectiva histórica. Argentina 1870-1952, Buenos Aires, Prometeo, 2006; recientemente, Ramacciotti, Karina y Carolina Biernat (eds.), Políticas sociales, entre demandas y resistencias. Argentina 1930-1970, Buenos Aires, Biblos, 2013.

${ }^{25}$ Poder Ejecutivo Nacional, Justicia e Instrucción Pública, Buenos Aires, Kraft, 1938.

${ }^{26}$ AHLJ, Diario de Sesiones de la Honorable Legislatura de la Provincia, Sesión del 27 de junio de 1942, p. 198.

${ }^{27}$ La Opinión, 14 de marzo de 1934, p. 3.
} 
Las zonas de la ciudad más afectadas solían ser las que estaban sobre el río Grande, como lo demostraban los índices periódicos de "La Viña", "Villa Elisa” y "Puente Otero", levantados por la Fundación Rockefeller en 1929, y por el Dr. Carlos Alvarado en 193128. Se realizaron estudios sobre epidemiología y profilaxis de la peste; se tendió en la frontera con Bolivia un cinturón sanitario para prevenir la expansión de la fiebre amarilla; se construyeron leprosarios y, en fin, se implementó en todo el territorio nacional un programa de higiene pública basado en la prevención de las enfermedades. Mirta Fleitas da cuenta de los procesos que en la década de 1930 concurrieron a la estructuración del sistema de salud pública en Jujuy, reconstruyendo la trama de los mismos en procura de interpretar las representaciones y prácticas que sustentaron el accionar de políticos y funcionarios, y arrojó con ello inapreciable luz al conocimiento de la realidad social en la provincia durante aquella etapa ${ }^{29}$.

Con características propias, los gobiernos provinciales procuraron secundar al Estado nacional en la implementación de políticas sociales. Un rasgo central del escenario político jujeño de la época era la particular simbiosis entre poder político y económico, cristalizada en la apabullante injerencia de los intereses vinculados a la industria azucarera en las estructuras del Estado provincial, a través del partido conservador, que no escatimó esfuerzos para neutralizar cualquier atisbo de movilización política —y sindical — de los trabajadores, para lo cual se persiguió - como en el resto del país - las actividades del comunismo. ${ }^{30}$ Una excepción fue el gobierno de Amadeo Sabattini en la provincia de Córdoba, que se constituyó en una verdadera "isla" de poder del Partido Radical, al reconocer a las organizaciones obreras y al sancionar una legislación garante de los derechos del trabajador, además de mejorar la capacidad del Estado para intervenir en las problemáticas sociales y especialmente en las sanitarias ${ }^{31}$. Otro caso peculiar fue el del gobierno del conservador Manuel Fresco en la provincia de Buenos Aires, quien hizo suya la concepción de la necesidad de un Estado activo y capaz de avanzar en la solución de los problemas para garantizar una creciente armonía social, que configurará lo que se ha dado en llamar como "populismo oligárquico"32.

\footnotetext{
${ }^{28}$ Fleitas, Mirta, Al rescate de vidas útiles. Salud pública en Jujuy durante los gobiernos de la Restauración Conservadora (1930-1940), Jujuy, Universidad Nacional de Jujuy, 2009. De 1915 a 1935, las intervenciones antimalaria adquirieron gran difusión en el país. Se instalaron Direcciones Regionales en las provincias, una de las cuales estaba en Jujuy. Su accionar estaba centrado en dos ámbitos: el ambiental, con proyectos de saneamiento, y el de la salud humana, para lo cual se crearon dispensarios encargados de la distribución de quinina. En 1933, el Dr. Alvarado inició una acción sistemática en el radio de la ciudad de Jujuy.

${ }^{29}$ Los planteos de la autora se abren a las perspectivas de una historia sociocultural de la salud y la enfermedad donde los condicionamientos del contexto son puestos en tensión con las experiencias del curar, del enfermar, del morir, que en ellos se inscriben.

${ }^{30} 17$ de los 18 diputados que integraban la Legislatura jujeña respondían al partido conservador, estando la mayoría vinculados a las compañías azucareras.

${ }^{31}$ En medio de una política de persecución al comunismo, el gobierno de Sabattini garantizó libertades y dejó actuar al Partido Comunista y a los gremios de esta orientación. Tcach, César, Amadeo Sabattini, Buenos Aires, Fondo de Cultura Económica, 1999.

${ }^{32}$ El plan orgánico de Fresco incluía la construcción de casas baratas para obreros, mejoras en las condiciones de trabajo, atención de la infancia abandonada, el cuidado de la salud y una educación disciplinante orientada a promover el amor a la patria y la adhesión al catolicismo. Véase Béjar, María Dolores, "El gobierno de Manuel Fresco. Entre la justicia social y el fraude patriótico", en Cuadernos del CISH, 2-3 (1997), pp. 79-124, «http:// www.fuentesmemoria.fahce.unlp.edu.ar/art_revistas/pr.2636/pr.2636.pdf» [consultado el 19 de enero de 2017].
} 
A lo largo del país, la Comisión Nacional de Ayuda Escolar impulsaría un proyecto de creación de servicios médicos en las escuelas de las provincias y los territorios nacionales, dirigidos por la Inspección Médica Escolar del Consejo Nacional de Educación, con el fin declarado de velar por la salud de los niños y vigilar la estricta observancia de las disposiciones legales sobre el particular. La iniciativa se había originado en la constatación de la total ineficacia de los servicios médicos en las 5000 escuelas que, a lo largo del país, dependían del Consejo Nacional. En los considerandos, se aludía al hecho de que

“[...] en el país se mantiene alta la cifra de la mortalidad infantil y un gran número de niños está mal alimentado, mal abrigado y vive en penosa promiscuidad: cuidar del niño es una exigencia perentoria del interés nacional"33.

Se resaltaba, a la vez, la "innegable pobreza de ciertas provincias" y las "zonas de verdadera miseria económica" aún existentes ${ }^{34}$. La Comisión sostenía comedores escolares en el Interior y el Consejo de Educación distribuía partidas alimentarias y repartía ropa y calzado, con lo que —según se afirmaba - se había logrado incrementar notoriamente las cifras de inscripción y de asistencia a las escuelas. Habiendo mostrado su eficiencia en la Capital Federal, se buscaba extender el servicio médico de la escuela primaria por toda la nación ${ }^{35}$. Este "verdadero servicio de asistencia social" incluía especialistas en medicina infantil y en enfermedades de origen contagioso o tóxico, apoyados por un equipo de "monitoras de higiene" que se desempeñaban como enfermeras visitadoras. Para Jujuy, donde en 1938 funcionaban 122 escuelas dependientes del Consejo Nacional de Educación, 85 escuelas fiscales provinciales y cuatro particulares -y donde se daba la cifra más baja de docentes primarios: 654 maestros en los distintos tipos de escuelas- se asignó un exiguo equipo de tres médicos, tres dentistas y tres visitadoras ${ }^{36}$.

Los informes de los inspectores seccionales enviados a recorrer las escuelas fiscales de la provincia constituyen reveladoras fuentes, pues permiten observar de cerca aristas que remiten a realidades complejas y brindan valiosas pistas sobre la cuestión de la deserción escolar. En 1940 una de estas inspecciones, realizada en la Escuela "Presidente Avellaneda" emplazada en el distrito suburbano de "La Viña", sobre la margen izquierda del Río Grande, daba cuenta de que

"El local se encuentra sin blanquear desde hace varios años. Es necesario el trabajo de nuevos pozos para los water-closet pues solo queda uno en condiciones, el que está al servicio exclusivo de la familia de la Directora [...]. Según el libro de matrícula se inscribieron 28 alumnos, pero solo tuvo

\footnotetext{
${ }_{33}^{33}$ Consejo Nacional de Educación, Educación común en la Capital, Provincias y Territorios Nacionales, Año 1938, Buenos Aires, Talleres Gráficos del Consejo de Educación, 1939.

${ }^{34}$ Ibídem.

${ }^{35}$ Hacia la década de 1930 el Consejo Nacional de Educación tenía jurisdicción en la Capital Federal y territorios nacionales. Bajo su órbita, en las provincias funcionaban las escuelas Láinez (llamadas así por el impulsor de la ley que, en 1905, dispuso la creación de escuelas primarias nacionales especialmente en regiones con altas tasas de analfabetismo). Al mismo tiempo, cada provincia tenía su propia organización de instrucción primaria.

${ }^{36}$ Consejo Nacional de Educación, Educación común... op. cit.
} 
una asistencia de tres a pesar del buen día. De los concurrentes dos, a pesar de ser segundo año de asistencia, solo saben las primeras palabras generadoras [...]. Al querer ejecutar algunas sumas con números dígitos no pudieron sin intervención del recuento de rayitas como quien va contando de uno en uno [...]. Según manifestación de la Sra. Directora, una de las causas de la inasistencia de los alumnos se debe a razones familiares ajenas a la escuela que ha motivado la resistencia de algunos padres de familia a enviar sus hijos a la misma, provocando así una asistencia como la actual" ${ }^{37}$.

En 1931 se había realizado en el país un Censo Escolar Nacional. En Jujuy, el total de alumnos censados había sido de 18988; de ellos, concurrían a la escuela 12721 (el 67\%). Existían en la provincia, por su parte, 3934 analfabetos en edad escolar..$^{38}$ Las cifras de analfabetismo se estimaban en la época en base a datos parciales, como los provenientes la lista de conscriptos y del padrón electoral. De acuerdo a información de este último (que contemplaba en la época a la población masculina nativa y naturalizada de 18 y más años de edad) la provincia de Jujuy tenía hacia 1938 una tasa de analfabetismo de 240 por 1000, mientras que a nivel del país la tasa era del 181 por 1000, y del 20 por 1000 en la Capital Federal.

En general, los indicadores económico-sociales incluyen — además del nivel de ingresoslos referidos a vivienda, junto a los de salud y educación. Más allá de los aspectos cuantitativos del problema habitacional eran motivo de preocupación los propiamente "cualitativos": insalubridad, precariedad, hacinamiento, ubicación en zonas inundables. Como ha señalado Óscar Yujnovsky, la vivienda es una "configuración de servicios que deben dar satisfacción a necesidades humanas primordiales: albergue, refugio, protección ambiental, espacio, vida de relación, seguridad, privacidad, identidad, accesibilidad física, entre otras" ${ }^{39}$. La calidad de los servicios habitacionales depende, además, del medio ambiente urbano. Hacia mediados de la década, podía leerse en un periódico local:

\footnotetext{
"En estos últimos días, como ocurre periódicamente, todo el agua viene sin filtrar, peor aún que la de los arroyos, en los que al menos corre cristalina; la que estamos bebiendo nosotros es calcárea, lechosa y de sabor nada agradable [...]. El mal parece que radica en el canal transportador de agua a la ciudad, el cual requiere mayor cauce y consiguientes construcciones que, por lo valiosas, se eluden" $"$.
}

\footnotetext{
${ }^{37}$ Archivo del Ministerio de Educación de la Provincia de Jujuy [en adelante, AMEJ], Consejo General de Educación de la Provincia de Jujuy, "Inspección a la Escuela № 28 Presidente Avellaneda", 20 de abril de 1940, exp. 46, ff. 2-3.

${ }^{38}$ Rojo, Bernabé, Crítica a los resultados generales publicados del censo escolar nacional de 1931, Buenos Aires, Talleres Gráficos de la Penitenciaría Nacional, 1932.

${ }^{39}$ Yujnovsky, Óscar, Claves políticas del problema habitacional argentino, 1955-1981, Buenos Aires, Grupo Editor Latinoamericano, 1984, p. 17.

${ }^{40}$ El Día, 17 de marzo de 1935, p. 3.
} 
Casi al cierre de nuestro período de análisis, en agosto de 1939, el gobernador Pedro Buitrago, en mensaje que acompañaba un proyecto de ley, hacía referencia a "continuos brotes palúdicos en las zonas periféricas por falta de sistemas cloacales convenientes"41.

\section{Pobrezas urbanas: los "otros" habitantes de la ciudad}

Los enfoques cuantitativos que aplican una mirada de macronivel suelen derivar sus conclusiones sobre el fenómeno de la pobreza de las características sociohistóricas de la comunidad en cuestión, con lo cual circunscriben el análisis a un determinado número de indicadores de las condiciones materiales de existencia. Tal perspectiva deja de lado indicios que permiten acceder a la percepción que sobre la propia situación tenían los sujetos. Un tipo particular de fuente documental nos ha posibilitado un camino de aproximación a las condiciones de la vida material de los estratos más bajos de los sectores populares jujeños, lo que ha develado algunas aristas de las experiencias subjetivas de quienes se autodefinían como "pobres". En efecto, las llamadas "cartas de pobreza" incluyen tanto la propia mirada sobre la situación de pobreza como la de otras personas de la misma comunidad. Se trata de solicitudes elevadas ante un juez para ser declarado "pobre" y quedar eximido del pago de los aranceles fijados para la iniciación de diversos trámites en las reparticiones públicas o para obtener algún tipo de beneficio social, como la provisión gratuita de remedios en un hospital. Estas fuentes contienen datos "objetivos" como edad del peticionante, ocupación económica o lugar de residencia, pero su riqueza proviene, sobre todo, de las referencias sobre condiciones de vida, situación familiar, medios de subsistencia, entre otra información esencialmente cualitativa. Si bien se trata de documentos generados en una situación particular (los testimonios llevan implícita la intención de conseguir un beneficio) este sesgo tiende, en todo caso, a neutralizarse debido a la cantidad de miradas concurrentes sobre una misma situación ${ }^{42}$.

Emplazada en un "asentamiento" conocido con el nombre de "Puerto Nuevo", que se extendía sobre tierras fiscales pertenecientes al municipio capitalino, “[...] la casa de Toribio Llampa tiene dos paredes hechas de madera y dos de chapa, igual el techo, y el suelo es de tierra apisonada. No tiene ventana y en invierno su familia pasa muchas horas en completa

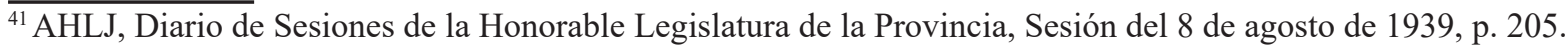

${ }^{42}$ La certificación de pobreza exigía las declaraciones de, al menos, tres testigos (no emparentados con el peticionante) que dieran fe de su condición de insolvencia. Estos no siempre eran vecinos del interesado, siendo frecuente que el mismo recurriera a compañeros de trabajo, a sus empleadores o, simplemente, a "conocidos de años". También se verificaban, ciertamente, situaciones similares a aquella que denunciaba una revista de circulación local: "El que implora caridad, asilo u hospitalización a las instituciones de socorro públicas, obtiene fácilmente amparo si su solicitud está refrendada por una persona vinculada o influyente. Se atiende la recomendación con preferencia a la necesidad ¡Sarcasmo del mundo! ¡La miseria debe ir garantida y acreditada!’. Vida Jujeña, septiembre de 1928, p. 11 .
} 
oscuridad" ${ }^{43}$. El anterior testimonio proviene de Isaías Vilte — también vecino de la zona- y testigo de Toribio Llampa en ocasión de solicitar este una "Carta de Pobreza" que acreditara su insolvencia. Los testimonios sobre las precarias condiciones del hábitat de quienes se habían "asentado" en esa área suburbana son por demás elocuentes. Así, la familia de Marcelino Tolay, compuesta de seis personas: esposa, suegra y tres hijos pequeños, "[...] viven en una pieza que les sirve de casa [...] y no tienen lugar demasiado para sus gallinas o algún rastrojo" ${ }^{4}$. Otro de los testigos presentados por este jornalero de 36 años contaba sobre el trabajo que debía realizar la suegra ("ya añosa") para contribuir a la subsistencia del grupo familiar: "[...] y amasa pan que lleva a vender por las casas del centro" 45 .

Pero atendamos la siguiente descripción, que proporciona una imagen de conjunto:

“[...] y esa zona, con estar próxima al cementerio, es de mucho cultivo de flores, pero yo [Zenón Guerrero] no he conseguido todavía permiso de la intendencia para plantar en el lote que está baldío al lado de los maíces de don Julián Reyes [...] no hay otro lugar vacío que ese, sin casas ni sembrado y en cualquier momento alguien viene y levanta su rancho ahí [...] unas hapas (sic.), unos ladrillos y ya, en cuantos días ya tenemos otros viviendo ahí [...] y el agua de la acequia que viene de San Pedrito es la única que hay en el lugar y pasa cerca del terreno que quiero sembrar. Otros tienen que buscarla de más lejos, ya veces piden en la escuela que es donde llega agua de la ciudad [...] y así estoy mientras muy pobre porque no consigo otro trabajo más que algunas cargas para llevar en mi mula a veces hasta Tilquisa o el Cucho [...]"46.

Este testimonio de Zenón Guerrero nos presenta un lugar donde se alternaban casas y terrenos de cultivo: flores pero también maizales — quizás se intercalaban algunos manchones de pastos, dado que él tenía una mula- No habla de las características de su propia casa, pero permite pensar en la precariedad que habría caracterizado a gran parte de las viviendas de la zona: "unas hapas (sic.), unos ladrillos y ya". Repárese en lo que se deja entrever sobre la disponibilidad de agua potable en aquel vecindario: "en la escuela que es donde llega agua de la ciudad". Por último, aunque Zenón no hace referencia a su familia, sabemos por los testigos que vivía con su mujer.

Ya casi hacia el cierre de nuestro período de análisis, un 4 de julio de 1942, las viviendas levantadas en estos parajes fueron erradicadas y sus habitantes trasladados a las tierras fiscales de una zona contigua al distrito de San Pedrito y cercana a la vez a la denominada "Villa Matadero", en lo que desde entonces se dio en llamar "Loteo Fiscal". La villa, que debía su nombre a su proximidad con el matadero municipal, fue otro de los lugares de localización

\footnotetext{
${ }^{43}$ Archivo Histórico de los Tribunales de Jujuy [en adelante, AHTJ], exp. 154, 3 de julio de 1933, sf. Las viviendas se emplazaban a ambos lados de las vías del ferrocarril, desde el cementerio hasta dar con la margen izquierda del Río Chico.

${ }^{44}$ AHTJ, exp. 73, 24 de abril de 1935, sf.

${ }^{45}$ Ibídem.

${ }^{46}$ AHTJ, exp. 146, 23 de octubre de 1939, sf.
} 
de los sectores populares pobres durante la década de 1930. Son numerosos los solicitantes de cartas de pobreza que declaraban tener allí su residencia. Así, por ejemplo, decía Cayetana Arroyo al testificar sobre el estado de indigencia de su vecina Encarnación Silisque y —de paso- también sobre su precaria situación: "Y es del caso decir que vivimos en un lugar muy humilde, como es esta villa del Matadero. Todas las casas son de adobes y techos de paja porque somos gente pobre de solemnidad sin recursos y que pasamos penurias tras penurias para conseguir el sustento diario [... $]^{\prime 47}$.

Descendiendo por el norte, hacia el otro extremo de la meseta de Nieva, este anillo de áreas suburbanas proseguía en la zona de "La Tablada". Allí tenía su vivienda Benjamín Ábalos, criador de 39 años, casado con Arminda Sajama, de 32, y de quienes se decía que "[...] viven penosamente a causa de tener que alimentar a una familia numerosa en estos tiempos donde falta el trabajo [...] a no ser por la ayuda de sus vecinos iban a volverse de nuevo a sus lugares [...] ella [Arminda] trabaja a veces en cocinar para una familia de la ciudad"48. En esta "zona de rancherío y ganado" - como la describiera hacia mediados de la década alguien preocupado por recuperar la estética del paisaje en torno al parque San Martín-49 se habían realizado durante décadas las famosas ferias de Pascua, a las que acudían arrieros con recuas de ganado seleccionado que se ubicaban en los corrales linderos.

Otro de los "lugares" de asentamiento de los estratos más bajos de los sectores populares urbanos jujeños era el área próxima a los Anexos del Ferrocarril, que se extendía hacia el sur y el este de la ciudad. Se trataba en este caso de terrenos de propiedad nacional, llamados en la época los "Bajos de la Estación". Allí, todavía en 1942, era posible hallar abundantes pasturas, y parecen no haber sido pocos los habitantes de la contigua Villa Belgrano que llevaban hasta esta zona sus haciendas. Era el caso de Santos Valdivieso y de Epifanio Cañari — solicitante y testigo de una certificación de pobreza-. Declaraba este último que "[...] lo conozco de llevar muchas veces juntos nuestros animales a los Bajos del ferrocarril [...] solo de ser criador vive él y su familia y es por esta razón su pobreza" ${ }^{50}$.

El universo de pobres urbanos no se agotaba en la cantidad de familias que, careciendo de propiedad, se asentaban en terrenos fiscales. Cabe también incluir entre ellos a tantos otros que, en su afán de permanecer en la ciudad, debían agolparse en los conventillos de cuya difusión en el corazón del casco céntrico citadino ya hemos dado cuenta. Los periódicos de la época -en general críticos tenaces de lo que veían como lugares privilegiados de "hacinamiento y promiscuidad" — ${ }^{51}$ se encargaban de resaltar la extracción social de quienes habitaban estos espacio colectivos, aludiendo alternativamente a las "pobres gentes explotadas por la avaricia

\footnotetext{
$\overline{{ }^{47} \text { AHTJ, exp. 224 }}, 11$ de diciembre de 1936, sf.

${ }^{48}$ AHTJ, exp. 231, 6 de octubre de 1932.

${ }^{49}$ El Día, 7 de agosto de 1935 , p. 4.

${ }^{50}$ AHTJ, exp. 34, 2 de marzo de 1942, sf.

${ }^{51}$ La Opinión, 11 de abril de 1934, p 4.
} 
del propietario" 52 o - las más de las veces- a "los elementos indeseables que en ellos se agolpan" ${ }_{53}$. Al solicitar Tomás Sope —-domiciliado en la calle Independencia 244 de la ciudadcertificación de su insolvencia, Cristóbal Chirino — declarando igual lugar de residenciacontaba "[...] que cuando uno de los hijos se enfermó todos los de la casa dieron algún dinero para los remedios, porque saben que nos le sobra ni un centavo [...]"54.

En julio de 1936, Trinidad Aramayo, de 34 años, residente en Villa Las Rosas, acudía ante los Tribunales de Jujuy a dar fe de la situación de pobreza e insolvencia de su vecina, Angélica Ovando, de 27, a quien

"[...] conoce desde hace varios años por quedar su casa a dos casas de la suya. Dice que la dicha Angélica solo vive del lavado que realiza para familias del centro, por estar su esposo [Pablo Sajama] enfermo en el hospital San Roque de esta ciudad [...] tiene que solventar sola la crianza de sus dos hijas pequeñas [...] dice que sin la ayuda de las vecinas no podría ni lavar para afuera por causa de que el frío le impide llevar a sus hijas al río $[\ldots]^{55 "}$.

Angélica era lavandera y llevaba la ropa de sus clientes al río Xibi-Xibi. Sabemos que era ese el lugar destinado a tales menesteres ${ }^{56}$. La temporada invernal (mes de julio) "le impide llevar a sus hijas al río". Atendamos por un momento a las palabras que el diputado Adrián Larrán pronunciara años atrás en el Recinto legislativo, ya que brindan una estampa —dramática — de la situación que enfrentaba la joven lavandera:

“[...] el proyecto lo ha inspirado la clase más humilde de este pueblo. Expuesta hasta ahora a las crueles contingencias del tiempo. Los señores diputados habrán tenido oportunidad de contemplar el triste cuadro que presentan madres de familia agobiadas del dolor y la miseria, buscando en el rudo trabajo del lavado un pedazo de pan para sus hogares. Realizan sus tareas a la intemperie en todo tiempo, sin ninguna comodidad que haga más llevadera tan ingrata tarea. Las enfermedades que contraen en esa ardua lucha por el sustento diario, tienen por corolario el triste fin de sus vidas $[\ldots]^{\prime 57}$.

\footnotetext{
${ }^{52}$ Ibidem.

${ }^{53}$ Crónica, Jujuy, 27 de febrero de 1936, p. 6. "En el "Conventillo de las 14 provincias" sito en calle Independencia 534, se estarían produciendo un sinnúmero de acontecimientos y líos a granel [...] ciertas personas de dudosa catadura que son las encargadas de armar escándalos a altas horas de la noche, cosa que trae la mala reputación del Conventillo". La Voz del Norte, 18 de enero de 1940, p. 5.

${ }^{54}$ AHTJ, exp. 218, 14 de agosto de 1938, sf. El subrayado es mío.

${ }^{55}$ AHTJ, exp. 105, 6 de julio de 1936, sf.

${ }^{56}$ Recoger ropas a domicilio y llevarlas a lavar al "Río Chico" a cambio de dinero "por tanto", era una actividad femenina muy extendida. Montalvetti, Martha, Una larga historia: Jujuy, su gente, Jujuy, Universidad Nacional de Jujuy, 1999.

${ }^{57}$ Lo que se proyectaba era la construcción de un lavadero público en la margen derecha del Río Chico. AHLJ, Diario de Sesiones de la Honorable Legislatura de la Provincia, Sesión del 31 de mayo de 1932, (diputado Adrián Larrán), p. 36.
} 


\section{La marginalidad persistente}

Uno de los últimos actos de la "restauración conservadora" fue el levantamiento del IV Censo Escolar, del Analfabetismo y de la Vivienda ${ }^{58}$. Los resultados pondrían en evidencia la magnitud del problema del hacinamiento en todas las regiones de Jujuy.

Hacia finales de la década, políticos e intelectuales reconocían la profundidad de la crisis habitacional argentina que adquiría magnitudes alarmantes en el noroeste del país. ${ }^{59}$ Unos años después de cerrado el período que nos ocupa, publicaba una revista jujeña:

\footnotetext{
"Nuestra ciudad capital padece desde hace largos años a esta parte, las argucias de la escasez de viviendas. Puede manifestarse, sin temor a caer en exageración, que la tercera parte de los habitantes no encuentran casa disponible para alquilar, viéndose obligados a hacinarse en cuartuchos reducidos y antihigiénicos" ${ }^{\prime 60}$.
}

De acuerdo al criterio censal, las familias que sufrían de "hacinamiento colectivo" eran aquellas que debían compartir casa con otras tres (o sea, cuatro familias conviviendo bajo un mismo techo). Se consideraba "hacinamiento individual" los casos de familias en que todos sus miembros dormían en una única pieza. En Jujuy, de un total de 20348 familias censadas en 1943, el 55,5\% padecía este tipo de hacinamiento. Como bien observaron quienes en la época analizaron los datos del censo, el hacinamiento individual traducía, de hecho, situaciones en que el núcleo familiar no solo dormía, sino también cocinaba, comía y hasta trabajaba en la misma habitación. ${ }^{61}$

En la ciudad de Jujuy, sobre un total de 3506 familias censadas, el 39,\% residía en viviendas de una sola pieza ${ }^{62}$. Todavía en 1944 una revista del medio brindaba una idea no tan solo de las condiciones de vida de los sectores más vulnerables sino también de la mirada prejuiciosa de los otros habitantes citadinos:

\footnotetext{
"De entre los problemas sociales de vastísimos alcances y que se agrava día a día en nuestra ciudad está el de las llamadas casas de inquilinato o, mejor dicho, los conventillos [...] exponentes de miseria, enfermedad y corrupción. En esta capital, pese a lo reducido de su radio urbano, existen infinidad de ellos
}

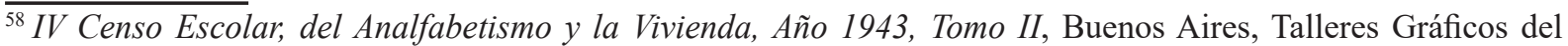
Consejo Nacional de Educación, 1948.

${ }^{59}$ Bunge, Alejandro, Una nueva Argentina, Buenos Aires, Kraft, 1940. Un panorama de la situación habitacional en la provincia de Jujuy hacia el período que nos ocupa puede hallarse en Jerez, Marcelo, "Expansión urbana y el problema de la vivienda en Jujuy en la primera mitad del siglo xx", en Teruel, Ana (dir.), Problemas nacionales en escalas locales. Instituciones, actores y prácticas de la modernidad en Jujuy, Rosario, Prohistoria, 2010, pp. 163200. El autor da cuenta de la evolución demográfica de Jujuy vinculando su dinámica con la crisis habitacional que padecía la provincia en el contexto de una problemática que abarcaba al conjunto del Noroeste argentino.

${ }^{60}$ Reflejos, 20 de mayo de 1944.

${ }^{61}$ Eran los "hogares de una sola pieza". Archivo General de la Nación, Dirección de Investigaciones Económicas y Sociales, Intervención Federal de Jujuy, Informe número 1, "El Grave Problema del Hacinamiento en la Ciudad de Jujuy", Jujuy, 1944.

${ }^{62}$ Ibídem.
} 
[...] no hablemos de los niños famélicos, semidesnudos, mugrientos, enfermos; no hablemos de la promiscuidad enervante, del hacinamiento bochornoso, de la falta de obras sanitarias o lo insuficiente de ellas" ${ }^{\prime 63}$.

Los resultados del referido Censo pondrían también en evidencia el grave problema del analfabetismo ${ }^{64}$. Jujuy registraba hacia principios de los años cuarenta una tasa del 366 por 1000 (la de Argentina era del 153 por 1000). En los Valles Centrales el índice alcanzaba el 258 por 1000; en los Valles Subtropicales el 399 por 1000, y la región de Quebrada y Puna registraba una altísima tasa del 435 por 1000. Un año antes del relevamiento censal, había advertido sobre la cuestión el Interventor Nacional Nicolás González Iramáin, al frente por entonces del gobierno:

\begin{abstract}
"Quienes hayan visitado alguna vez, sin previo aviso, las escuelas primarias de los barrios obreros de la ciudad de Jujuy, y algunas de los lugares apartados de la campaña - y tengan el espíritu y los ojos abiertos, el corazón no endurecido por el egoísmo, y la cabeza libre de absorbentes y frías especulaciones mercantiles- comprenderán sin esfuerzo el decreto que expedimos, tan pronto como presenciamos el triste cuadro, el 16 de marzo de 1942, disponiendo que el Consejo General de Educación tomara inmediatamente las medidas necesarias para suministrar leche y pan a todos los niños que concurren a las escuelas primarias de la provincia, y algunas ropas de abrigo a los que fueren hijos de padres indigentes, y admitirán también que a ese fin hayamos empleado fondos que no tenían tal expreso destino en el presupuesto oficial, sin llamarnos por eso —como lo hizo el señor vicegobernador electo de Jujuy [Luis María Oliver] en su carta abierta - malversadores de caudales públicos [...] ¡Ojalá malversaran de este modo y siempre todos los gobernantes de provincia!" ${ }^{65}$.
\end{abstract}

\title{
5. Conclusiones
}

Las repercusiones en la sociedad de la crisis económica mundial de 1929 colocaron en un lugar privilegiado de la agenda oficial del Gobierno argentino a la llamada "cuestión social". Desde el Estado se pusieron en funcionamiento, a lo largo del territorio nacional, estructuras administrativas destinadas a intervenir en áreas como la educación, la salud y la vivienda. Nos propusimos aquí reconstruir algunos de los derroteros de estas políticas en una

\footnotetext{
${ }^{63}$ Reflejos, 25 de marzo de 1944.

${ }^{64}$ Debe hacerse la salvedad de que el censo únicamente consideró a la población de 0 a 21 años y a sus padres o tutores.

${ }^{65}$ González Iramáin, Nicolás, Tres Meses en Jujuy, Buenos Aires, Kraft, 1942.
} 
comunidad urbana que, hacia los años de la llamada "restauración conservadora", se ajustaba a los parámetros utilizados para caracterizar a las sociedades como "tradicionales", debido tanto a los datos objetivos de las estadísticas como a las precarias condiciones de la vida material de gran parte de su población. A medida que avanzaba el análisis nuevas fuentes venían a revelar las complejas y cambiantes formas que podía asumir el "sujeto popular" destinatario de estas políticas, de acuerdo a la perspectiva elegida para captarlo, lo que ha fortalecido la presunción de que los resultados concretos de las políticas sociales implementadas por los gobiernos conservadores de la década de 1930 habrían alcanzado, en todo caso, a las capas superiores de los sectores populares, al hacer a los más pobres objeto de un asistencialismo que paliaba solo discontinua y ocasionalmente el hambre o la desnudez. Así, por ejemplo, la política sanitaria nacional y provincial canalizada en Jujuy, como en el resto del país, a través de la infraestructura educativa, quedaba fuera del alcance de gran número de familias imposibilitadas — por motivos de subsistencia vinculados probablemente a la utilización de mano de obra infantil— de enviar a sus hijos a la escuela. Tampoco las proyectadas "viviendas baratas para empleados y obreros" -cuya adquisición dependía de la posibilidad de ofrecer las garantías del acceso a un salario regular - podían solucionar el grave problema habitacional del crecido número de desocupados y trabajadores a jornal.

Con la expectativa de contribuir a dilucidar la trama de factores que median entre la disposición de los actores estatales para desplegar políticas de intervención en la esfera social y la capacidad de las mismas de impactar en las capas de la población a las que van dirigidas, ensayamos una aproximación a las condiciones de vida de aquellos sectores populares que habitaron la ciudad de Jujuy en esos años críticos y que, por diversos motivos, permanecieron al margen de los mecanismos de integración social implementados desde el Estado.

Planteada la cuestión a partir del caso que nos ha ocupado, quizás podamos contribuir a esclarecer el curso que siguieron en la misma época los procesos en otros espacios del país mientras que, por involucrar prácticas y modos de comportamiento susceptibles de desarrollarse en cualquier sociedad, podrían aplicarse a situaciones históricas menos convergentes. Podría tratarse - como gustan de señalar los microhistoriadores-de experiencias humanas susceptibles de iluminar a otras y plantear cuestiones trasladables a diferentes espacios y tiempos. Ha dicho una vez Marshall Sahlins, a propósito de su relato hawaiano, que incluso las historias de remotas islas pueden echar luz sobre el mundo social de occidente: "de pronto aparece un mundo de cosas nuevas para tener en cuenta" ${ }^{6}$.

\footnotetext{
${ }^{66}$ Sahlins, Marshall, Islas de Historia. La muerte del Capitán Cook. Metáfora, antropología e historia, Barcelona, Gedisa, 1988, p. 79 .
} 